\title{
MAXILLARY SINUS ASSESSMENT FOR GENDER AND AGE DETERMINATION USING CONE BEAM COMPUTED TOMOGRAPHY IN AN EGYPTIAN SAMPLE
}

\author{
Siraj S. Najem ${ }^{1 *} B D S$, Wael M. Safwat ${ }^{2} P h D$, Rania A. ELAziz ${ }^{3} P h D$, Yousria S. Gaweesh ${ }^{4} P h D$.
}

\begin{abstract}
INTRODUCTION: Forensic anthropology is the application of the medical science in the criminal law. The identification of human skeletal remains is considered the first challenging and important step of unknown skull and very crucial for further analysis. In forensic medicine the adult skeleton gender determination is usually the first step of the identification process.

OBJECTIVES: The primary aim of this study was to assess the possibility of using cone beam computed tomography (CBCT) images for gender and age determination through the evaluation of maxillary sinus linear measurements, the second aim to determine the prevalence of maxillary sinus septa and to detect the most common shape of maxillary sinus.

MATERIALS AND METHODS: The present study was conducted in Department of Oral Medicine, Periodontology, Oral Diagnosis and Oral Radiology, Faculty of Dentistry, Alexandria University. Retrospectively 82 CBCT scans of Egyptian patients aged 20-65 years were included in a cross-sectional study that was designed to measure three parameters (height, width and length) of maxillary sinus bilaterally in axial and coronal view using On-Demand ${ }^{\circledR}$ software. Moreover estimation of the prevalence of maxillary sinus septa and evaluation of maxillary sinus morphology was performed.

RESULTS: The studied sample showed statistically insignificant differences $(p>0.05)$ in maxillary sinus measurements between males and females and between maxillary sinus measurements according to age group. Sinus septa were present in 78 (47\%) of the 164 maxillary sinuses, and according to the maxillary sinus morphology the main 3D shape was pyramidal shape in (upside down triangle) in $100 \%$ of the cases.
\end{abstract}

CONCLUSIONS: linear measurements of maxillary sinus on the CBCT images cannot be used for gender or age determination. KEYWORDS: CBCT, Gender determination, Septa prevalence, Maxillary sinus morphology.

RUNNING TITLE: Maxillary sinus assessment in gender determination using CBCT.

1. BDS,2010, Faculty of Dentistry, Benghazi University, Libya.

2. Associate Professor of Oral Radiology Department, Faculty of Dentistry, Mansoura University, Mansoura, Egypt.

3. Associate Professor of Oral Medicine, Periodontology, Oral Diagnosis and Radiology Department, Faculty of Dentistry, Alexandria University, Alexandria, Egypt.

4. Professor of Oral Medicine, Periodontology, Oral Diagnosis and Radiology Department, Faculty of Dentistry, Alexandria University, Alexandria, Egypt.

*Corresponding author:

E-mail: sirajsalehnajem@gmail.com.

\section{INTRODUCTION}

Forensic anthropology is the application of the medical science in criminal law. The identification of human skeletal remains of unknown skulls is considered the first challenging and important step and is crucial for further analysis (1).

In mass disasters like terrorist attacks, plane crashes, explosions, earthquakes and warfare, the identification of unknown individuals is very difficult and depends on the available bones and their conditions (1-2). The determination of gender can be done through various body parts, like the skull (3), pelvis (1) and, frontal sinuses (4). As evident from earlier studies the most helpful area of the body for comparative radiography is the cranium (5), where the skull is the most dimorphic and easily sexed portion of skeleton after pelvis, providing accuracy up to $92 \%$ (1). It has been reported that the gender can be determined with an accuracy of $100 \%$ if skeleton exists completely, $98 \%$ from both the pelvis and the skull, 95\% from the pelvis only or the pelvis and long bones, 90-95\% from both skull and long bones $80-90 \%$ from long bones only. Forensic investigators receives unknown skeletal remains, the key is to use bones that remain intact, like maxillary sinuses $(6,7)$.

Radiographs are indispensable tools that are used in forensic anthropology; radiographic method is the simplest and cheapest method for gender and age determination when compared to the other methods like the histological and biochemical methods. The accuracy of measurements on radiographs is based on the quality of the radiographs (8). Maxillary sinus radiography has been used for determination of gender and age. It has been reported that Computed Tomography (CT scans) is an excellent imaging modality in the identification of unknown remains and are used a gold standard to evaluate the true anatomy of sinuses (9), it also provides an accurate assessment of the paranasal sinuses and craniofacial bones (10). CT linear measurements of maxillary sinuses are very useful and can be used in determination of gender and age in forensic medicine. However, their use is 
limited because of high cost, and because of their restricted accessibility.

With the introduction of CBCT, these drawbacks have been overcome (planning with minimal radiation dose and artifacts). Cone beam computed tomography (CBCT) is an Xray beam and detector system that moves around the part of the body being examined. CBCT is the preferred choice of methodology for diagnosis in almost all fields of dentistry including forensic dentistry (11).

Cone beam computed tomography is highly accurate and reproducible in linear measurements in the axial and coronal image planes and in different areas of the maxillofacial region (8). CBCT can visualize and provide precise information about teeth and surrounding complex anatomical structures, as it is characterized by rapid volumetric image acquisition with high resolution and low dose radiation level. The crucial benefit of CBCT is overcoming the limitations of conventional radiography by producing $3 \mathrm{D}$ images that allow a comprehensive evaluation of the anatomy of the region of interest (12), these advantages of CBCT make it a reliable tool in dental researches.

The maxillary sinus is the largest and the first paranasal sinus to develop. It is a pneumatic space that is located in the body of the maxilla bilaterally and opens in the middle nasal meatus of the nasal cavity with single or multiple openings. It consists of two pyramidal shaped air filled cavities lined with mucosa (13-14). There are various shapes of maxillary sinus, that is, triangular, leaf, scapular, and renal shaped (15), it has been reported that triangular sinuses were the most common in both females and males (15). The sinus measures about $8 \times 4 \mathrm{~mm}$ at birth, and is situated with its longer dimension directed anteriorly and posteriorly (16). The average dimensions of the adult maxillary sinus are 25-35 mm in width, 36-45 $\mathrm{mm}$ in height, and 38-45 $\mathrm{mm}$ in length (17). It develops at the tenth to eleventh weeks of intrauterine life. The maxillary sinus enlarges variably and greatly by pneumatization until it reaches the adult size by the eruption of the permanent teeth (16). The maxillary sinus tends to be stable after the second decade of life and thus, reliable measurements can be achieved by radiographic images after the age of 20 years (11).

Maxillary sinus septa are barriers of cortical bone, described as an inverted gothic arch arising from the inferior or lateral walls of the maxillary sinus that divide the sinus floor into multiple compartments, known as recesses (16-18). These septa were first analyzed by Arthur S. Underwood, an anatomist who reported their prevalence and characteristics and these septa were afterwards, referred to as Underwood's septa (18).

To the best of our knowledge, most of the studies of gender and age determination by maxillary sinus linear measurements, and for determination of the maxillary sinus morphology and for detection the prevalence maxillary sinus septa have been performed using CT scan images. Only a few studies using CBCT imaging modality have been reported till date.

\section{MATERIALS AND METHODS 1. Study design}

A retrospective study was conducted on eighty two CBCT images with age range between 20 years and 65 years old, all CBCT images were selected from Department of Oral Radiology, Faculty of Dentistry, and Alexandria University. An approval was obtained from the ethics committee at the faculty of dentistry, Alexandria University, Egypt (IRB 00010556)-(IORG 0008839).

\section{Sample Size}

A sample size of 82 CBCT images were required to detect an area under ROC curve (AUC) of 0.70 relative to a null value of 0.50 , as statistically significant with $80 \%$ power and at a significance level of 0.05 . The sample size was calculated using Medcalc program version 12.2.1.0 (19).

\section{Criteria for patient selection \\ Inclusion Criteria}

- Cone beam computed tomography images already taken for implant, root canal treatment or extraction.

- Images with good resolution.

- The study included the CBCT images for patients between age 20 to 65 years

- Some images included patients with loss of the upper posterior teeth (missed one tooth or more than one tooth).

\section{Exclusion Criteria}

- Known cases of maxillary pathologies like (tumors, odontogenic lesions, bone lesions, traumatic injuries) were excluded from the study.

- Patients with injuries or fractures affecting the maxillary sinus.

- Scans of patients less than 20 years of age were excluded because of the maxillary sinus tends to be stabilize after second decade of life.

Patients with idiopathic maxillary sinus pneumatization.

Images of low resolution quality.

- Distortion of images or presence of any artifacts.

- Patients with history of any oral-maxillofacial surgical intervention in the area of maxillary sinus.

\section{Radiographic examination}

Each linear measurement was recorded with the help of OnDemand $^{\circledR}$ software at two times in two different measurement sessions with an interval of one week to minimize memory bias. Then the mean value of each two records was taken.

The mean and the standard deviation for each measurement in each side were calculated, and compared statistically between male and female groups to determine if there was any statistical difference between genders. Also mean and standard deviation were compared in patients younger and older than 40 years to predict the age. Evaluation of the presence of septa and detection the maxillary sinus morphology was done. All results were tabulated.

\section{Measurements}

The height of the maxillary sinus was measured on the frontal plane, while the length and width measurements were measured on the axial planes.

- The height was measured from the inner wall of the anterior borders of maxillary sinus, as the longest distance between the lowest points of the floor of the sinus to the highest point of the roof of the sinus in the coronal view (Fig.1). 
- The width was the greatest distance horizontally from the medial surface to the most lateral point of maxillary sinus in the axial view (Fig. 2, A).

- The length (Depth) was defined as the longest distance from the most anterior point of the medial wall to the posterior point of maxillary sinus in the axial view (Fig. 2, B).

Maxillary sinuses were evaluated for presence of septa, and for the morphology of the maxillary sinus through CBCT.

\section{CBCT images}

Cone beam computed tomography images of the maxillary sinus were obtained using I-CAT machine (Imaging science International, 2nd generation, Hatfield, PA, USA).

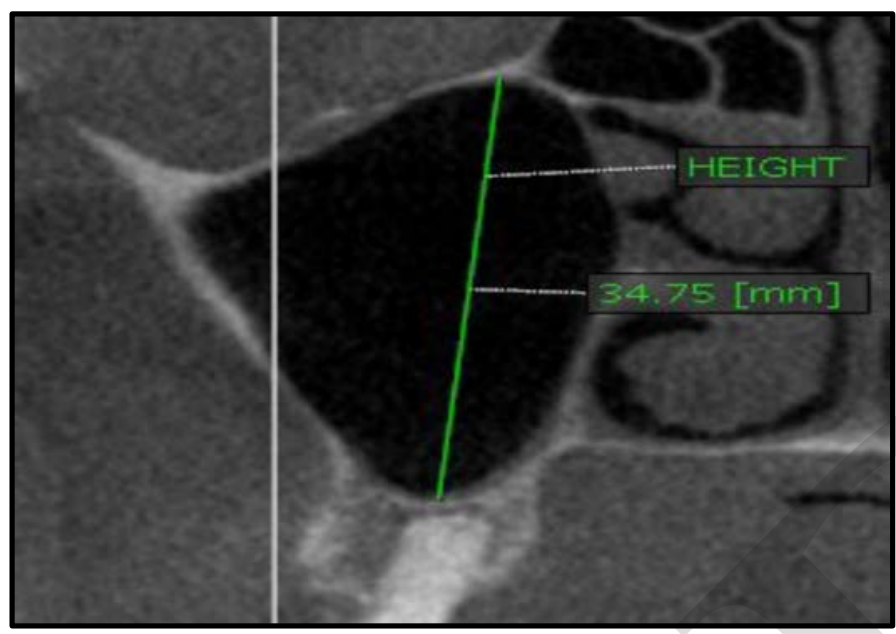

Figure (1): Height of the maxillary sinus on coronal view.

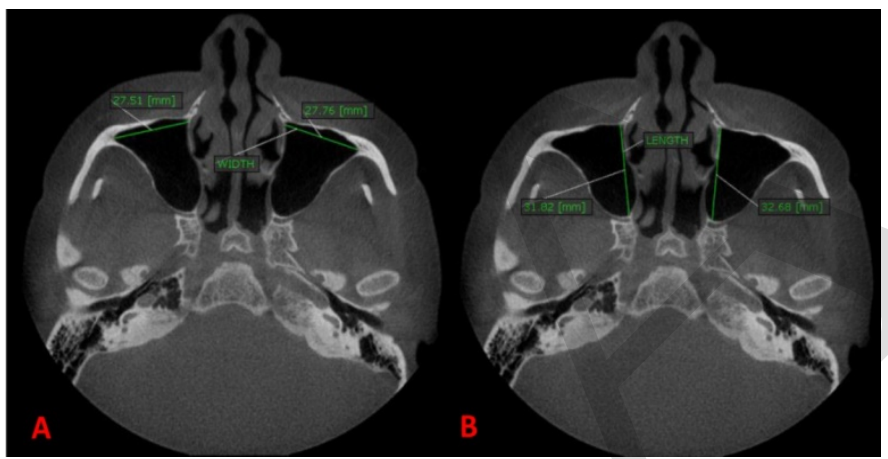

Figure (2): A) Showed the width of the maxillary sinus on axial view. B) Showed the length of the maxillary sinus on axial view.

\section{Statistical analysis}

Data were collected and entered to the computer using SPSS (Statistical Package for Social Science) program for statistical analysis (ver 21) (IBM Corp, Armonk, NY, USA). Data were entered as numerical or categorical, as appropriate. The Kolmogorov-Smirnov test of normality revealed no significance in the distribution of the variables, so the parametric statistics was adopted (20). Data were described using minimum, maximum, mean, standard deviation and 95\% CI of the mean. Comparisons were carried out between two studied independent normally distributed variables using independent sample t test (21). When Levene's test for equality of variances was significant, Welch's t-test was used, which is an adaptation of Student's t-test, and is more reliable when the two samples have unequal variances and unequal sample sizes (22). Comparisons were carried out between the two studied groups dependent on normally distributed variables using paired t-test. Bar chart with 95\% error bar graph was used accordingly.

An alpha level was set to 5\% with a significance level of $95 \%$, and a beta error accepted up to $20 \%$ with a power of study of $80 \%$.

\section{RESULTS}

The present study was carried out to evaluate the linear measurements of maxillary sinuses.

The $\mathrm{p}$ value of the height of right maxillary sinus was 0.068 that means there was no statistical significant difference between males and females. Similarly, the $p$ value of the height of left maxillary sinus was 0.160 indicating that there was no statistical significant difference between males and females on that side as well.

With respect to the width of right maxillary sinus the $p$ value was 0.764 and for the left maxillary sinus it was 0.628 which means that there was no statistical significant difference between males and females with respect to this variable on either side of the jaw.

Furthermore, the p value of the length of right maxillary sinus was 0.256 and for the left maxillary sinus it was 0.465 . Both values mean that there was no statistical significant difference between males and females with respect to this variable on either side of the jaw.

The $\mathrm{p}$ value of the height of right maxillary sinus was 0.330 and for the height of left maxillary sinus left maxillary sinus it was 0.989 that means there was no statistical significant difference between patients younger and older than 40 years of age with respect to this variable bilaterally.

The $p$ value of the width of right maxillary sinus was 0.169 and for the right maxillary sinus it was 0.084 , which means there was no significant difference between patients younger and older than 40 years of age with respect to maxillary sinus width.

The $\mathrm{p}$ value of the length of right side maxillary sinus was 0.879 and for the right side it was 0.469 . This means there was no statistical significant difference between patients younger and older than 40 years of age with respect to maxillary sinus length bilaterally.

\section{Prevalence of Septa}

A total of 82 patients were analyzed through cone beam computed tomography (CBCT). Therefore, a total of 164 maxillary sinuses were included in this study. The number of maxillary sinus septa was determined. Septa were found in about $47 \%$ of total sinuses.

The present study concluded that maxillary sinus septa could be present unilaterally or bilaterally, and maxillary sinus could have one or more septa (Fig.3).

\section{Right maxillary sinus septa}

Septa in the right maxillary sinuses were found in 42 sinuses, about $51 \%$ of all right maxillary sinuses. Divided into 20 male, about $64 \%$ of all males in the present study had right maxillary sinus septa, and in 22 female, about $43 \%$ of all females in the present study had right maxillary sinus septa. 


\section{Left maxillary sinus septa}

Septa in the left maxillary sinuses were found in 35 sinuses, about $42 \%$ of all left maxillary sinuses. Divided into 15 male, about $48 \%$ of all males in the present study had left maxillary sinus septa, and in 20 female, about $39 \%$ of all females in the present study had left maxillary sinus septa.

\section{Maxillary sinus morphology}

Maxillary sinus was classified in to five different anterior shapes (23): Type 1 (triangular), Type 2 (upside down triangle), Type 3 (square), Type 4 (irregular) and Type 5 (rectangular). These shapes were identified in the anterior view.

The main 3D shape of bilateral maxillary sinuses identified according to the above classification was Type 2 which is (upside down triangle). There was no association between gender and shape in the current study.

In the present study the most common maxillary sinus 3D morphology found in this Egyptian population sample was the pyramidal shape in $100 \%$ of all images that were analyzed, (Type 2) according to Rennie (23) classification (Fig.4).

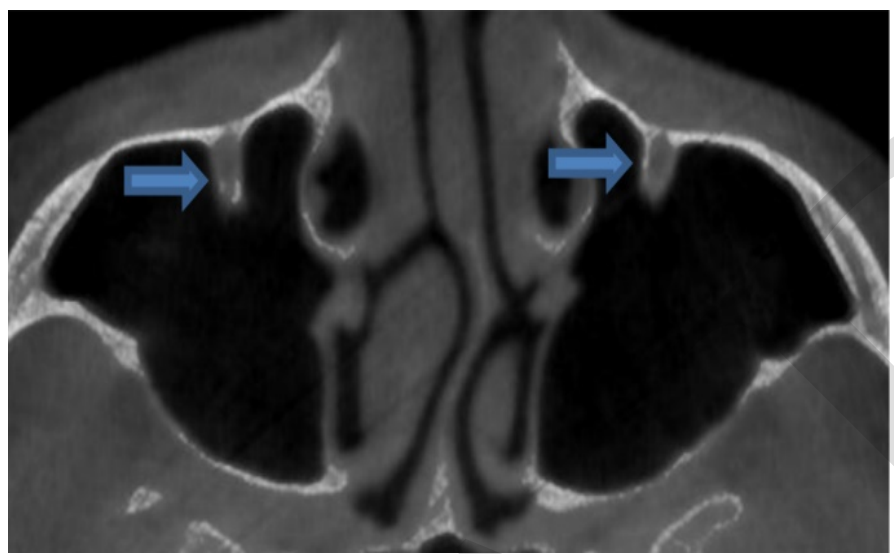

Figure (3): Shows presence of Intra-sinus septa in anterior region maxillary sinus bilaterally. (Axial view of CBCT).

Table (1): Show comparison between males and females according to the height, width, and length of right and left maxillary sinus.

\begin{tabular}{|c|c|c|c|c|c|c|c|c|c|}
\hline \multirow{5}{*}{$\begin{array}{c}\text { Height } \\
\text { (mm) }\end{array}$} & & Sex & $\mathbf{N}$ & $\begin{array}{l}\text { Min- } \\
\text { Max }\end{array}$ & Mean & SD & $\begin{array}{c}95 \% \\
\text { CI } \\
\text { for } \\
\text { mean }\end{array}$ & $t$ & P \\
\hline & \multirow{2}{*}{$\begin{array}{l}\text { The height } \\
\text { of right } \\
\text { maxillary } \\
\text { sinus }\end{array}$} & Male & 31 & $\begin{array}{r}19.29- \\
46.94 \\
\end{array}$ & 35.73 & 6.26 & $\begin{array}{r}33.433- \\
\mathbf{3 8 . 0 2 2} \\
\end{array}$ & \multirow[b]{2}{*}{$\begin{array}{c}\mathrm{t}_{\mathrm{w})(\mathrm{d}=43.908)}= \\
1.871\end{array}$} & \multirow[b]{2}{*}{$\begin{array}{c}p=0.068 \\
\text { NS }\end{array}$} \\
\hline & & Female & 51 & $\begin{array}{r}24.61- \\
41.71 \\
\end{array}$ & 33.40 & 3.84 & $\begin{array}{l}32.318- \\
34.476 \\
\end{array}$ & & \\
\hline & \multirow{2}{*}{$\begin{array}{l}\text { The height } \\
\text { of left } \\
\text { maxillary } \\
\text { sinus }\end{array}$} & Male & 31 & $\begin{array}{r}20.24- \\
47.39 \\
\end{array}$ & 35.25 & 6.61 & $\begin{array}{r}32.828- \\
37.675 \\
\end{array}$ & \multirow{2}{*}{$\mathrm{t}_{(\mathrm{df}=80)=1.418}$} & \multirow[b]{2}{*}{$\begin{array}{c}p=0.160 \\
\text { NS }\end{array}$} \\
\hline & & Female & 51 & $\begin{array}{r}24.42- \\
44.27 \\
\end{array}$ & 33.48 & 4.66 & $\begin{array}{l}32.174- \\
34.795\end{array}$ & & \\
\hline \multirow{5}{*}{$\begin{array}{l}\text { Width } \\
\text { (mm) }\end{array}$} & & Sex & $\mathbf{N}$ & $\begin{array}{r}\text { Min } \\
\text {-Max }\end{array}$ & Mean & SD & $\begin{array}{c}95 \% \\
\text { CI } \\
\text { for } \\
\text { mean }\end{array}$ & t & $\mathrm{P}$ \\
\hline & \multirow{2}{*}{$\begin{array}{l}\text { The width } \\
\text { of right } \\
\text { maxillary } \\
\text { sinus }\end{array}$} & Male & 31 & \begin{tabular}{|l|}
$14.23-$ \\
35.74 \\
\end{tabular} & 26.79 & 5.49 & \begin{tabular}{|l|}
$24.781-$ \\
28.807
\end{tabular} & \multirow{2}{*}{$t_{(\mathrm{df}=80)}=0.301$} & \multirow[b]{2}{*}{$\begin{array}{c}p=0.764 \\
N S\end{array}$} \\
\hline & & Fema & 51 & $\begin{array}{l}13.98- \\
38.27 \\
\end{array}$ & 26.41 & 5.63 & \begin{tabular}{|l|}
$24.827-$ \\
27.996 \\
\end{tabular} & & \\
\hline & \multirow{2}{*}{$\begin{array}{l}\text { The width } \\
\text { of left } \\
\text { maxillary } \\
\text { sinus }\end{array}$} & Male & 31 & $\begin{array}{l}11.95- \\
36.53 \\
\end{array}$ & 25.89 & 5.93 & \begin{tabular}{|l|}
$23.719-$ \\
28.067 \\
\end{tabular} & \multirow{2}{*}{$\mathrm{t}_{(\mathrm{df}=80)=0.486}$} & \multirow[b]{2}{*}{$\begin{array}{c}p=0.628 \\
N S\end{array}$} \\
\hline & & Female & 51 & \begin{tabular}{|l|}
$12.81-$ \\
40.48 \\
\end{tabular} & 26.55 & 5.99 & \begin{tabular}{|l|}
$24.868-$ \\
28.238 \\
\end{tabular} & & \\
\hline $\begin{array}{l}\text { Length } \\
\text { (mm) }\end{array}$ & & Sex & $\mathbf{N}$ & $\begin{array}{c}\text { Min } \\
\text {-Max }\end{array}$ & Mean & SD & $\begin{array}{c}95 \% \\
\text { CI } \\
\text { for } \\
\text { mean }\end{array}$ & $\mathbf{t}$ & $\mathrm{P}$ \\
\hline
\end{tabular}

\begin{tabular}{|c|c|c|c|c|c|c|c|c|}
\hline \multirow{2}{*}{$\begin{array}{l}\text { The length } \\
\text { of right } \\
\text { maxillary } \\
\text { sinus }\end{array}$} & Male & 31 & \begin{tabular}{|l|}
$20.25-$ \\
42.33 \\
\end{tabular} & 35.69 & 4.76 & \begin{tabular}{|c|}
$33.946-$ \\
37.441 \\
\end{tabular} & \multirow[b]{2}{*}{$\mathrm{t}(\mathrm{df}=80)=0.1 .143$} & \multirow[b]{2}{*}{$\begin{array}{c}p=0.256 \\
N S\end{array}$} \\
\hline & Female & 51 & \begin{tabular}{|l|}
$24.86-$ \\
42.55 \\
\end{tabular} & 34.59 & 3.92 & \begin{tabular}{|c|}
$33.482-$ \\
35.689
\end{tabular} & & \\
\hline \multirow{2}{*}{$\begin{array}{l}\text { The length } \\
\text { of left } \\
\text { maxillary } \\
\text { sinus }\end{array}$} & Male & 31 & \begin{tabular}{|l|}
$28.26-$ \\
44.22
\end{tabular} & 36.39 & 3.88 & \begin{tabular}{|c|}
$34.972-$ \\
37.815
\end{tabular} & \multirow{2}{*}{$\mathrm{t}_{(\mathrm{df}=80)=0.735}$} & \multirow[b]{2}{*}{$\begin{array}{c}p=0.465 \\
N S\end{array}$} \\
\hline & Female & 51 & \begin{tabular}{|l|}
$18.95-$ \\
44.20
\end{tabular} & 35.66 & 4.67 & \begin{tabular}{|c|}
$34.347-$ \\
36.972
\end{tabular} & & \\
\hline
\end{tabular}

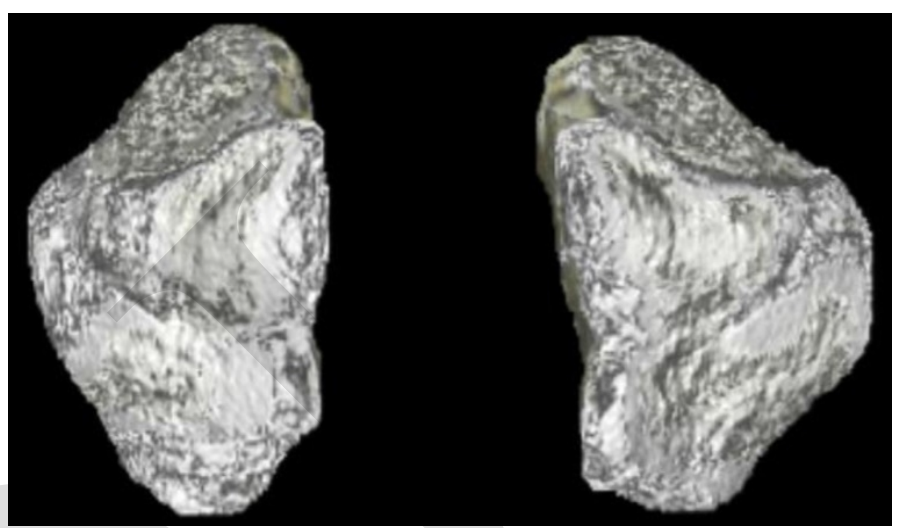

Figure (4): Shows the pyramidal 3d shape of maxillary sinus bilaterally onCBCT using the OnDemand software.

Table (2): Show comparison between patients younger and older than 40 years old according to the height, width, and length of right and left maxillary sinus.

\begin{tabular}{|c|c|c|c|c|c|c|c|c|c|}
\hline & & $\begin{array}{l}\text { Age 40 } \\
\text { OR } \\
\text { more }\end{array}$ & $\mathbf{N}$ & $\begin{array}{l}\text { Min- } \\
\text { Max }\end{array}$ & Mean & SD & $\begin{array}{l}95 \% \\
\text { CI for } \\
\text { mean }\end{array}$ & t & $P$ \\
\hline \multirow{5}{*}{$\begin{array}{r}\text { Height } \\
(\mathrm{mm})\end{array}$} & \multirow{2}{*}{\begin{tabular}{|c|}
$\begin{array}{c}\text { The height } \\
\text { of right } \\
\text { maxillary } \\
\text { sinus }\end{array}$ \\
\end{tabular}} & $<=40$ & 60 & \begin{tabular}{|l|}
$22.26-$ \\
42.81 \\
\end{tabular} & 33.95 & 4.56 & $\begin{array}{c}\text { 32.7732- } \\
35.1300\end{array}$ & \multirow[t]{2}{*}{$\mathrm{t}_{(\mathrm{w})(\mathrm{df}=80)}=0.980$} & \multirow{2}{*}{$\begin{array}{c}p=0.330 \\
\text { NS }\end{array}$} \\
\hline & & $>40$ & 22 & \begin{tabular}{|l|}
$19.29-$ \\
46.94 \\
\end{tabular} & 35.17 & 6.03 & $\begin{array}{c}32.4975- \\
37.8438 \\
\end{array}$ & & \\
\hline & \multirow{2}{*}{$\begin{array}{c}\text { The height } \\
\text { of left } \\
\text { maxillary } \\
\text { sinus }\end{array}$} & $<=40$ & 60 & \begin{tabular}{|l|}
$20.87-$ \\
44.27 \\
\end{tabular} & 34.15 & 5.28 & $\begin{array}{c}32.7847- \\
35.5105 \\
\end{array}$ & \multirow[t]{2}{*}{$\mathrm{t}_{(\mathrm{df}=80)}=0.014$} & \multirow[b]{2}{*}{$\begin{array}{c}p=0.989 \\
\text { NS }\end{array}$} \\
\hline & & $>40$ & 22 & \begin{tabular}{r|}
$20.24-$ \\
47.39 \\
\end{tabular} & 34.17 & 6.22 & $\begin{array}{c}31.4085- \\
36.9260\end{array}$ & & \\
\hline & & $\begin{array}{c}\text { Age } \\
40 \\
\text { OR } \\
\text { more }\end{array}$ & $\mathbf{N}$ & $\begin{array}{l}\text { Min- } \\
\text { Max }\end{array}$ & Mean & SD & $\begin{array}{l}95 \% \\
\text { CI for } \\
\text { mean }\end{array}$ & $\mathbf{t}$ & $\mathbf{P}$ \\
\hline \multirow{5}{*}{$\begin{array}{r}\text { Width } \\
(\mathrm{mm})\end{array}$} & \multirow{2}{*}{$\begin{array}{l}\text { he width } \\
\text { of right } \\
\text { maxillary } \\
\text { sinus }\end{array}$} & $<=40$ & 60 & \begin{tabular}{|l|}
$13.98-$ \\
38.27
\end{tabular} & 27.07 & 5.83 & $\begin{array}{l}25.5629- \\
28.5755\end{array}$ & \multirow{2}{*}{$\mathrm{t}_{(\mathrm{df}=80)=1.390}$} & \multirow{2}{*}{$\begin{array}{c}p=0.169 \\
\text { NS }\end{array}$} \\
\hline & & $>40$ & 22 & \begin{tabular}{|l|}
$16.25-$ \\
34.95
\end{tabular} & 25.16 & 4.52 & $\begin{array}{l}\text { 23.1561- } \\
27.1612\end{array}$ & & \\
\hline & \multirow{2}{*}{$\begin{array}{l}\text { he width } \\
\text { of left } \\
\text { maxillary } \\
\text { sinus }\end{array}$} & $<=40$ & 60 & \begin{tabular}{|c|}
$11.95-$ \\
40.48
\end{tabular} & 26.95 & 6.09 & $\begin{array}{l}25.3803- \\
28.5257\end{array}$ & \multirow[b]{2}{*}{$\mathrm{t}_{(\mathrm{df}=80)}=1.651$} & \multirow{2}{*}{$\begin{array}{c}p=0.084 \\
\text { NS }\end{array}$} \\
\hline & & $>40$ & 22 & \begin{tabular}{|l|}
$15.67-$ \\
36.53
\end{tabular} & 24.53 & 5.24 & $\begin{array}{l}22.2116- \\
26.8566\end{array}$ & & \\
\hline & & $\begin{array}{c}\text { Age } \\
40 \text { OR } \\
\text { more }\end{array}$ & $\mathbf{N}$ & $\begin{array}{l}\text { Min- } \\
\text { Max }\end{array}$ & Mean & SD & $\begin{array}{l}95 \% \\
\text { CI for } \\
\text { mean }\end{array}$ & t & $\mathbf{P}$ \\
\hline \multirow{4}{*}{$\begin{array}{c}\text { Length } \\
(\mathrm{mm})\end{array}$} & \multirow{2}{*}{$\begin{array}{l}\text { he length } \\
\text { of right } \\
\text { maxillary } \\
\text { sinus }\end{array}$} & $<=40$ & 60 & $\begin{array}{l}20.25- \\
42.55\end{array}$ & 35.05 & 4.27 & $\begin{array}{r}33.9466- \\
36.1509\end{array}$ & \multirow{2}{*}{$\mathrm{t}_{(\mathrm{df}=80)}=0.153$} & \multirow{2}{*}{$\begin{array}{c}p=0.879 \\
\text { NS }\end{array}$} \\
\hline & & $>40$ & 22 & $\begin{array}{l}24.86- \\
38.84 \\
\end{array}$ & 34.89 & 4.36 & $\begin{array}{r}32.9526- \\
36.8174 \\
\end{array}$ & & \\
\hline & \multirow{2}{*}{$\begin{array}{l}\text { he length } \\
\text { of left } \\
\text { maxillary } \\
\text { sinus }\end{array}$} & $<=40$ & 60 & $\begin{array}{l}18.95- \\
44.22 \\
\end{array}$ & 36.15 & 4.68 & $\begin{array}{r}34.9422- \\
37.3600 \\
\end{array}$ & \multirow{2}{*}{$\mathrm{t}_{(\mathrm{df}=80)=0.728}$} & \multirow{2}{*}{$\begin{array}{c}p=0.469 \\
\text { NS }\end{array}$} \\
\hline & & $>40$ & 22 & $\begin{array}{l}28.26- \\
40.90\end{array}$ & 35.35 & 3.44 & $\begin{array}{r}33.8303- \\
36.8788\end{array}$ & & \\
\hline
\end{tabular}

\section{DISCUSSION}


In forensic anthropology determination of gender and age by morphological assessment has been represented to be one of the oldest procedures (6). Identification the remains of human skeletons are an important challenge step and one of the most difficult approaches in forensic medicine. The method may vary and depends on the available bones and their conditions. Maxillary sinus radiography has been used for identification of skeletal remains and for determination of gender and age; however, levels of sexual dimorphism are population specific due to a combination of genetic and environmental factors. CBCT provide highly accurate linear measurements, thus the present study was designed to evaluate the reliability and accuracy of maxillary sinus dimensions measurement for gender and age determination using CBCT of 82 patient images. Results of our study have indicated that there was no statistical significant difference in maxillary sinus height, width, and length between male and female groups. And there was no statistically significant difference between patients younger and older than 40 years of age.

Unlike the facts pointed out by Uthman et al., (24), who found that the maxillary sinus height was the best discriminant parameter that could be used to study sexual dimorphism with an overall accuracy of $71.6 \%$. And what was obtained by Amin and Hassan (25), who reported that height measurement of the maxillary sinus is the most reliable predictor of gender with a correct predictive accuracy of $70.8 \%$ in males and $62.5 \%$ in females respectively, the present study showed that height measurements was not statistically significant values.

On the other hand Azhar et al., (26), showed that the left maxillary sinus width was the best discriminate parameter (with an overall accuracy of 61.3\%) and diameters of the maxillary sinus can be used successfully as an adjunct tool for sex determination, inconsistent to the present study that showed width measurements was not statistically significant different values.

In the Vidya et al., (27) study, significant statistical difference was found in the right maxillary sinus volume between males and females. The present study did not measure maxillary sinus volumes.

In another study conducted by Sharma et al., (28), the maxillary sinus length was the best discriminant parameter with an overall accuracy of $69.81 \%$, which is in disagreement to the present study that showed length measurements was not statistically significant values.

In another study by Bangi et al., (29), concluded that gender determination can be done using measurements of maxillary sinus with an overall accuracy rate of $88 \%$. This result coincides with result obtained by Ekizoglu et al., (30), who reported that morphometric analysis of maxillary sinuses will be helpful for gender determination with an overall accuracy rate of maxillary sinus was $77.15 \%$. Similar results obtained by Prabhath et al., (7) who reported an overall accuracy rate of $83.3 \%$ in predicting gender. Teke et al., (6), also found that significant difference in the width, height and length of the maxillary sinuses between males and females have an accuracy level rate of $69.3 \%$.

In a study by Fernandes (5), reported that maxillary sinus of males were found narrower than female in Zululand and wider in males than females in Europe. In contrast, the current study showed that there was no statistical difference between females and males.

The results of the present study were different from other previous studies; all of previous studies used CT scan for evaluation of maxillary sinus measurement in gender and age determination, which carries high radiation exposure to the patients and also relatively high cost.

However, other studies used CBCT as Tambawala et al., (31) study, who concluded that maxillary sinus height was the best discriminant parameter with overall accuracy of $71.6 \%$.

Conversely, to many studies conducted, Saccucci et al., (32), reported a study on gender determination using maxillary sinus by means of CBCT. No statistical difference was found in patient's maxillary sinus volumes between genders and they concluded that it is not possible to use the maxillary sinus to discern sexual difference in corpse identification. This is in agreement with conclusion of the present study that showed maxillary sinus measurements not used in gender and age determination

Most authors have reported significant differences in the measurements of maxillary sinus between males and females. Where Saccucci et al., (32) reported no such differences, similar to our results that reject the hypothesis of maxillary sinus measurements can determine gender and age, and showed no statistical significant difference between males and females in relation to the right and the left maxillary sinus length, height dimensions and width dimensions, and between maxillary sinus measurements and age groups.

Our findings concerning evaluation of the maxillary measurement in gender and age determination are different from the results of most of previous studies that carried out in the different population. These differences may be explained by combination of many factors like regional diversity in the morphometric characteristics among various populations all over the world, which may have an influence on the outcome of morphological studies.

Another factor for these differences between the results of the studies may be due to variations of measurement methods, sample sizes and to different ethnic and racial groups. This variation among different populations may have resulted from the difference in genetic traits, foods, habits, post infections and environmental factors, these factors resulting distinct anatomic features like differences in body stature, skeletal size, height and difference in osteoclastic and osteoplastic activity and pneumatization process of maxillary sinus, which can affect the sizes of maxillary sinus. Additionally, differences in the imaging soft wares and different radiographic machines utilized in studies may also contribute to this variation as most of the previous studies have been conducted on different soft wares and different of CT scans machines.

The results of the present study revealed that sinus septa were found in about $47 \%$ of total sinuses were analyzed. Prevalence of septa in the right side was more than the left side with a higher prevalence in males than females.

The results of the CT evaluation of the maxillary sinus septa in the other studies are not consistent with those of the present one. On the other hand, the prevalence of maxillary sinus septa with use of CBCT is nearly close to the results obtained 
by the present study. The prevalence of sinus septa was reported to be $55.2 \%$ by Ilgüy et al., (33), $58 \%$ as found by Orhan et al., (19) and $47 \%$ as reported by Neugebauer et al., (34), in another study, Lana et al., (35), stated that the prevalence of antral septa was $44.4 \%$.

Few studies analyzed the shape of the maxillary sinus. The maxillary sinus varies according to age, sex, and population groups; however there are limited studies that have illustrated its $3 \mathrm{D}$ form over time.

The present study evaluated the morphology of the maxillary sinus by use of CBCT, and found that there was no any association between gender or age and shape, and concluded that the main shape identified on the right and left maxillary sinuses of Egyptian population sample was pyramidal shape (Type 2 according to Rennie classification) (23) in $100 \%$ of images that were analyzed. These results are similar to those by Kim et al., (36), who reported that Type 2 was the most prevalent sinus morphology in the Korean sample.

To date, no similar study conducted on the Egyptian population has been reported. Therefore, the aim of the current study was to evaluate the reliability of maxillary sinus measurements for gender and age determination by analyzing CBCT images. The study sample only included Egyptian patients in order to avoid variations arising from ethnicity. This could explain why the results may not coincide with other studies that were conducted on different populations. Results of the present study showed that there were no difference in the mean values for most of the studied measurements in males and females.

\section{CONCLUSION}

In conclusion this study shows that the maxillary sinus linear measurements of height, width, length did not show any significant difference between males and females and was not a reliable discriminant parameter that could be used for the purpose of sex discrimination.

\section{CONFLICT OF INTEREST}

The authors declare that they have no conflicts of interest.

\section{REFERENCES}

1. Saini V, Srivastava R, Rai RK, Shamal SN, Singh TB, Tripathi SK. Mandibular ramus: an indicator for sex in fragmentary mandible. J Forensic Sci. 2011. 2011;56:S13-6.

2. Scheuer L. Application of osteology to forensic medicine. Clin Anat.2002;15:297-312.

3. Günay Y, Altinkök M, Çagdir S, Kirangil B. Gender determination with skull measurements. J Forensic Med. 1997;13:13-9.

4. Cameriere R, Ferrante L, Mirtella D, Rollo FU, Cingolani M. Frontal sinuses for identification: quality of classifications, possible error and potential corrections. J Forensic Sci. 2005;50:770-3.

5. Fernandes CL. Forensic ethnic identification of crania: The role of the maxillary sinus - A new approach. Am J Forensic Med Pathol. 2004;25:302-13.

6. Teke HY, Duran S, Canturk N, Canturk G. Determination of gender by measuring the size of the maxillary sinuses in computerized tomography scans. Surg Radiol Anat. 2007; 29:9-13.
7. Prabhat M, Rai S, Kaur M, Prabhat K, Bhatnagar P, Panjwani S. Computed tomography based forensic gender determination by measuring the size and volume of the maxillary sinuses. J Forensic Dent Sci. 2016;8:40-6.

8. Malik M, Laller S, Saini RS, Mishra RK, Hora I, Dahiya N. Mental foramen: An Indicator for Gender Determination-A Radiographic Study. Santosh Univ J Health Sci. 2016;2:12-4.

9. Moshfeghi M, Tavakoli MA, Hosseini ET, Hosseini AT, Hosseini IT. Analysis of linear measurement accuracy obtained by cone beam computed tomography (CBCTNewTom VG). Dent Res J (Isfahan). 2012;9:S57-62.

10. Cagici CA, Yilmazer C, Hurcan C, Ozer C, Ozer F. Appropriate interslice gap for screening coronal paranasal sinus tomography for mucosal thickening. Eur Arch Otorhinolaryngol. 2009;266:519-25.

11. Miracle AC, Mukherji SK. Conebeam CT of the head and neck, part 2: clinical applications. AJNR Am J Neuroradiol. 2009;30:1285-92.

12. Kiarudi AH, Eghbal MJ, Safi Y, Aghdasi MM, Fazlyab M. The applications of cone-beam computed tomography in endodontics: a review of literature. Iran Endod J. 2015;10:16-25.

13. Lawson W, Patel ZM, Lin FY. The development and pathologic processes that influence maxillary sinus pneumatization. Anat Rec (Hoboken). 2008;291:1554-63.

14. Misch CE, Resnik RR, Misch-Dietsh F. Maxillary Sinus Anatomy, Pathology, and Graft Surgery. In: Misch CE. (ed). Contemporary Implant Dentistry. $3^{\text {rd }}$ ed. St. Louis: Mosby Elsevier; 2008.

15. Wolf G, Anderhuber W, Kuhn F. Development of the paranasal sinuses in children: implications for paranasal sinus surgery. Ann Otol Rhinol Laryngol.1993;102: 705-11.

16. Faramarzie M, Babaloo AR, Ghertasi Oskouei S, Faramarzie M. Prevalence, height, and location of antral septa in Iranian patients undergoing maxillary sinus lift. J Perio Imp Dent. 2009;1:43-7.

17. Saccucci M, Cipriani F, Carderi S, Di Carlo G, D'Attilio M, Rodolfino D, et al. Gender assessment through threedimensional analysis of maxillary sinuses by means of Cone Beam Computed Tomography. Eur Rev Med Pharmacol Sci. 2015;19:185-93.

18. Orhan K, Kusakci Seker B, Aksoy S, Bayindir H, Berberoğlu A, Seker E. Cone beam CT evaluation of maxillary sinus septa prevalence, height, location and morphology in children and an adult population. Med Princ Pract. 2013;22:47-53.

19. MEDCALC $\AA$ easy-to-use statistical software. MedCalc Statistical Software Version 14.8.1 (2014) MedCalc Software Bvba, Ostend. Available at: http://www.medcalc.org.

20. Field A. Discovering Statistics Using IBM SPSS Statistics. $4^{\text {th }}$ ed. London, California, New Delhi: SAGE Publications Ltd; 2013.

21. Welch BL. The generalization ofstudent's' problem when several different population variances are involved. Biometrika. 1947;34:28-35. 
22. Ruxton GD. The unequal variance t-test is an underused alternative to Student's t-test and the Mann-Whitney U test. Behav Ecol. 2006;17:688-90.

23. Rennie C, Haffajee MR, Satyapal KS. Shape, Septa and Scalloping of the Maxillary Sinus. Int J Morphol. 2017;35:970-8.

24. Uthman AT, Al-Rawi NH, Al-Naaimi AS, Al-Timimi JF. Evaluation of maxillary sinus dimensions in gender determination using helical CT scanning. J Forensic Sci. 2011;56:403-8.

25. Amin MF, Hassan EI. Sex identification in Egyptian population using multidetector computed tomography of the maxillary sinus. J Forensic Leg Med. 2012;19:65-9.

26. Azhar A, Ibrahim G, Salah F. Ct scan images analysis of maxillary sinus dimensions as a forensic tool for sexual and racial detection in a sample of kurdish population. Eur Sci J. 2015;11:271-81.

27. Vidya CS, Shamasundar N, Manjunatha B, Raichurkar K. Evaluation of size and volume of maxillary sinus to determine gender by 3D computerized tomography scan method using dry skulls of south Indian origin. Int J Cur. 2013;5:97-100.

28. Sharma SK, Jehan M, Kumar A. Measurements of maxillary sinus volume and dimensions by computed tomography scan for gender determination. J Anat Soc India 2014;63:36-42.

29. Bangi BB, Ginjupally U, Nadendla L, Vadla B. 3D Evaluation of Maxillary Sinus Using Computed Tomography: A Sexual Dimorphic Study. Int J Dent. 2017; 2017:9017078.
30. Ekizoglu O, Inci E, Hocaoglu E, Sayin I, Kayhan FT, Ozgur I. The use of maxillary sinus dimensions in gender determination: A thin-slice multidetector computed tomography assisted morphometric study. J Craniofac Surg. 2014;25:957-60.

31. Tambawala SS, Karjodkar FR, Sansare K, Prakash N. Sexual dimorphism of maxillary sinus using cone beam computed tomography, Egypt J Forensic Sci. 2015;6:120-25.

32. Saccucci M, Cipriani F, Carderi S, Di Carlo G, D'Attilio M, Rodolfino D, et al. Gender assessment through threedimensional analysis of maxillary sinuses by means of cone beam computed tomography. Eur Rev Med Pharmacol Sci. 2015;19:185-93.

33. Ilgüy D, Ilgüy M, Dolekoglu S, Fisekcioglu E. Evaluation of the posterior superior alveolar artery and the maxillary sinus with CBCT. Braz Oral Res. 2013;27:431-7.

34. Neugebauer J, Ritter L, Mischkowski RA, Dreiseidler T, Scherer P, Ketterle M, et al. Evaluation of maxillary sinus anatomy by cone-beam CT prior to sinus floor elevation. Int J Oral Maxillofac Implants. 2010;25:258-65.

35. Lana JP, Carneiro PM, Machado Vde C, de Souza PE, Manzi FR, Horta MC. Anatomic variations and lesions of the maxillary sinus detected in cone beam computed tomography for dental implants. Clin Oral Implants Res. 2012;23:1398-403.

36. Kim HJ, Yoon HR, Kim KD, Kang MK, Kwak HH, Park HD, et al. Personal computer based three-dimensional reconstruction and simulation of maxillary sinus. Surg Radiol Anat. 2003;24:393-9. 